\title{
EXPERIMENTAL-NUMERICAL CALIBRATION OF THE FRACTURE LOCUS OF WEATHERING STEEL
}

\author{
FRANCO CONCLI \& LORENZO MACCIONI \\ Faculty of Science and Technology, Free University of Bolzano-Bozen, Italy
}

\begin{abstract}
Weathering steel, specifically Cor-Ten (or CORTEN) steel is a material particularly exploited in the last century for various outdoor applications, e.g. bridges, building facades, artworks etc. In addition to a tensile strength comparable with other construction steels, the natural oxide of this material, that is common rust, has the same specific volume as the metallic core. This ensures the adhesion of the oxidized protective layer as for aluminium. Therefore, the stable rust layer protects the raw material from further corrosion. This characteristic overcomes the need for painting and maintenance. These properties boost the exploitation of Cor-Ten in several civil applications, also where safety is a fundamental requirement, e.g. guard rails used, for example, in the South-Tyrolean region along the highways. With the aim of verifying or optimizing such safety applications, it is important to know the ductile behavior of the material. Indeed, during an impact, the main purpose of the structure is to absorb energy and this implies that large deformations will take place. Experimental quasi-static tests were performed on several sample geometries made of Cor-Ten. The same tests were also numerically reproduced, to retrieve the actual stress state, quantify the plastic strain at failure and calibrate a ductile damage model. The material model is based on both the classical incremental model of plastic response with isotropic hardening and the phenomenological concept of damage in continuum mechanics.

Keywords: ductile fracture, Cor-Ten, fracture locus, experimental, FEM.
\end{abstract}

\section{INTRODUCTION}

In 1933, US Steels launched a new self-passivating steel (weathering steel) with $\mathrm{Cu}, \mathrm{Cr}$ and $\mathrm{P}$ in the alloy [1]. To underline its remarkable resistance to CORrosion and to TENsile stress, the new material was called Cor-Ten and its composition underwent some adjustments in the following years [2]. However, its strength properties were not the promoters of its exploitation and interest in research. Indeed, the anticorrosive and passivating characteristics of this material inspired engineers, architects and artists to use this material. Cor-Ten was initially exploited in the railway sector [3] in order to reduce the corrosion of wagons. It was also used in the construction of bridges [4] with the aim of reducing the need of painting and maintenance. Its application extends to building facades [5] for aesthetic reasons and in many outdoor artworks e.g. [6].

Researchers focused on its corrosion behavior under different environmental conditions [7]-[9]. Indeed, Cor-Ten requires special conditions to create a protective layer; these are wet/dry cycles [10]. This phenomenon is negatively affected by the harmful action of $\mathrm{Cl}^{-}$, as may occur close to the marine environment [11] and by $\mathrm{SO}_{2}$, associated with high humidity especially in polluting environment [12]. Moreover, the corrosion behavior was studied with varying alloy elements [13], metal microstructures [14] and surfaces finish [15].

Nowadays, the safety barriers (guardrail) of the Brenner Highway [16] and in most of the South-Tyrolean region are made in Cor-Ten. Firstly, its natural color presents a low visual impact (with respect to the galvanized alternative) in a UNESCO world heritage such as this alpine region. Secondly, the maintenance costs are expected to be low.

Despite experimental tests being conducted to homologate the Cor-Ten guardrail installations [17], in some specific areas this application is not exempt from corrosion [18]. 
Therefore, it is possible that the installation has undergone geometric changes capable of compromising the safety of the structure, especially during a crash impact.

In the light of the above considerations, it is essential to fine-tune an FE modeling of the crash behavior of the Cor-Ten barriers to assert their safety performance [19] both in their initial conditions and after their eventual modifications undergone by maintenance and/or corrosion. Furthermore, the model could be exploited for traffic accident reconstruction. In addition, since the functional goal of safety barriers is "to absorb as much impact energy as possible through their deformation and at the same time maintain their integrity" [20] having a characterization of the Cor-Ten plastic and fracture behavior is fundamental to developing these models.

The work presented in this paper represents the first step towards fine-tuning an FE model able to describe the crash behavior of traffic barriers made of Cor-Ten. Therefore, the present paper aims to characterize the ductile behavior of the Cor-Ten through experimental quasistatic tests with different geometries thus different level of triaxiality. The same tests were also numerically reproduced, to retrieve the actual stress state, quantify the plastic strain at failure and calibrate a ductile damage model.

\section{MATERIALS AND METHODS}

The material of the study is a Cor-Ten Weathering steel. In order to characterize the behavior of the material, dedicated tensile tests were performed on a MTS Criterion 45 testing machine. The machine is capable to apply loads up to $100 \mathrm{kN}$.

In order to determine the relevant constitutive law, 4 mono-axial tests were performed on smooth samples (Fig. 1). Applied force, crosshead displacement as well as deformation, measured with an extensometer, were acquired.

While for the elastic region the $\sigma-\varepsilon$ relation can be derived directly from the measurements, in the plastic (hardening) region, an inverse numerical procedure is required. Several simulations were performed and the F-s (Force-crosshead displacement) curve (Fig. 2) obtained is numerically compared with the measured one. The constitutive relation can be described by the Voce law [21], [22].

$$
\sigma=C_{1}+C_{2}\left(1-e^{-C_{3} \varepsilon_{p}}\right)+C_{4} \varepsilon_{p}
$$

where constants $C_{i}(i=1,4,2,3)$ are the yielding stress, the linear coefficient, the exponential coefficient and the so-called exponential saturation parameter, respectively, and $\varepsilon_{p}$ is the accumulated plastic strain (Table 1).

In this way, with an iterative procedure, it is possible to calibrate the constitutive law.

Several ductile damage models have been developed over the years. One of the first works was carried out by Mirza et al. [23]. They studied the influence of the stress triaxiality using copper specimens concluding that the strain triaxiality plays a fundamental role in the failure of metals. Other models were proposed by Rice and Tracey [24], Hancock and Mackenzie [25] and Johnson and Cook [26]. All these models propose a relation between the maximum plastic strain at fracture $\varepsilon_{\text {peeq }}$ and the triaxiality $\eta$. Triaxiality is a parameter that well represents the state of stress and is defined as:

$$
\eta=\frac{\sum \frac{\sigma_{i}}{3}}{\sqrt{\frac{1}{2}\left[\sum\left(\sigma_{i}-\sigma_{j}\right)^{2}\right]}} .
$$




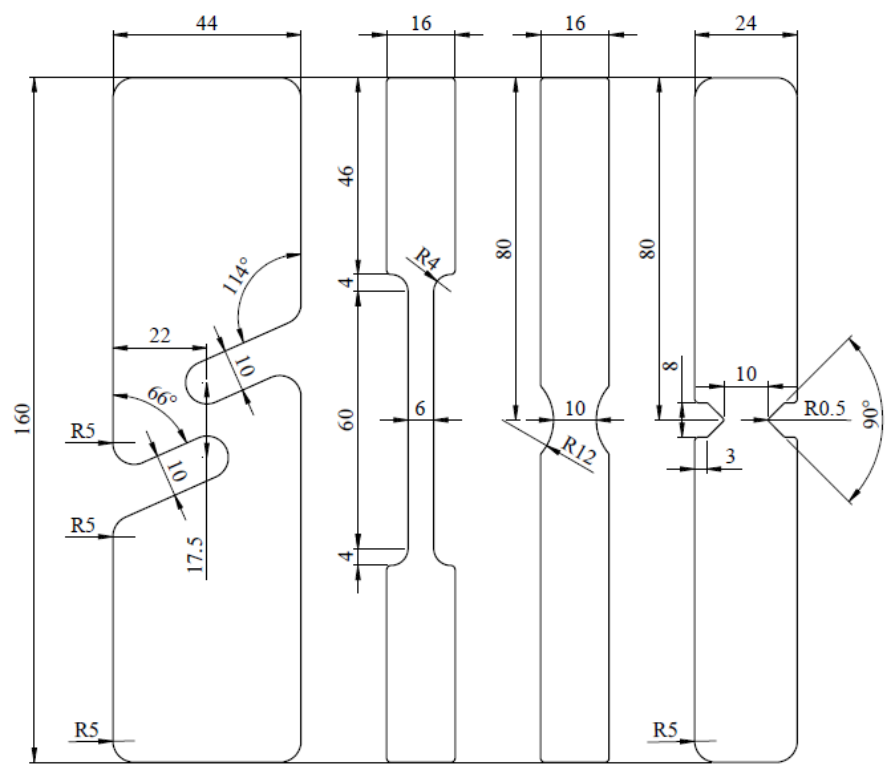

Figure 1: Geometries of the samples.

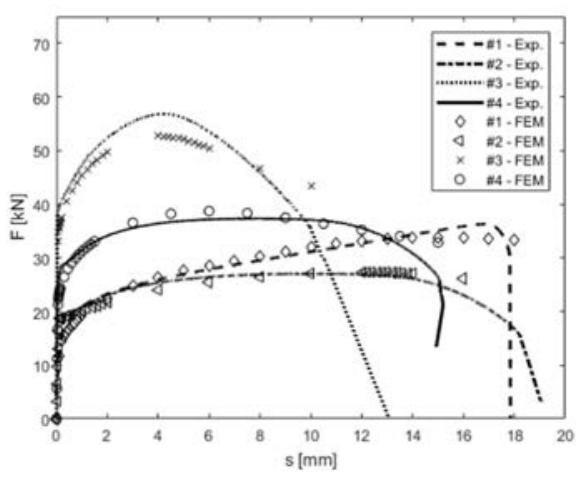

(a)

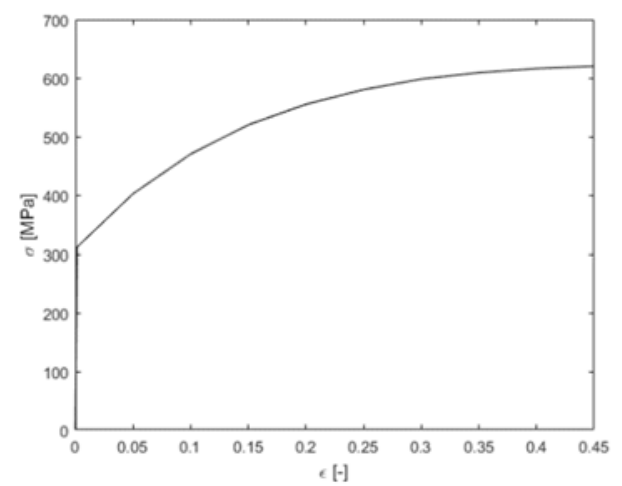

(b)

Figure 2: (a) F-s relation - comparison between numerical and experimental curves; and (b) True stress-true strain curve.

Table 1: Voce hardening parameters for the Cor-Ten steel.

\begin{tabular}{|c|c|c|c|}
\hline$C_{1}(\mathrm{MPa})$ & $C_{2}(\mathrm{MPa})$ & $C_{3}(-)$ & $C_{4}(\mathrm{MPa})$ \\
\hline 320 & 380 & 5 & 500 \\
\hline
\end{tabular}

The relation proposed by Rice and Tracey [24] is an exponential decreasing function. Starting from this work, Hancock and Mackenzie [25] and, successively, Johnson and Cook 
[26] proposed new relations able to take into consideration the effects of temperature and strain-rate. Further studies by Bao [27]-[30], performed on aluminium samples, have shown that the effect of the triaxiality cannot be modelled with a monotonic function. Different triaxiality levels are associated with different failure mechanisms (Fig. 3).

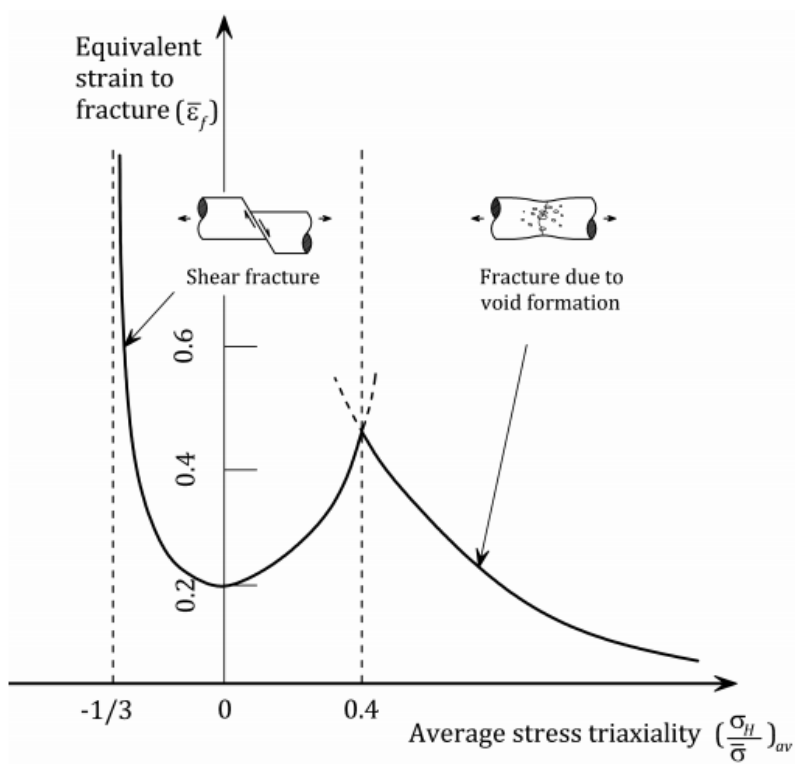

Figure 3: Influence of stress triaxiality on the equivalent strain to fracture. Adapted from [31].

It is possible to subdivide the triaxiality axis into three main regions. At low levels of triaxiality, the failure is mainly due to shearing; for high levels of triaxiality, the fracture is mainly due to the nucleation-growth-coalescence mechanism. In the intermediate region, the fracture originates due to a combination of the two mechanisms.

In this preliminary stage of the research, low triaxiality range of a Cor-Ten steel was studied. Further investigations are planned in order assess the $\eta-\varepsilon_{\text {peeq }}$ relation also for higher values of triaxiality. Effects of strain rate and temperature were also neglected.

The sample geometries used to calibrate the ductile fracture model are shown in Fig. 1. The experimental tests were performed up to the rupture of the sample itself. The same geometries were reproduced numerically [32]-[33] by means of the open-source free solver Code-Aster. The choice of an open-source tool was made because it allows more flexibility with respect to close-source commercial software, making it possible to customise the code with the implementation of specific models for the analysis of the physical problem of interest. Simulations were interrupted in correspondence to the imposed displacement that has been shown experimentally to cause failure (Figs. 4-7). From the numerical results, the value of equivalent plastic strain at fracture $\varepsilon_{p e e q}$ and the triaxiality $\eta$ at the same point were obtained (Fig. 8). The values are shown in Table 2.

The equation describing the fracture locus (Fig. 9) results in:

$$
\varepsilon_{\text {peeq }}=38.592 \cdot \eta^{2}-20.611 \cdot \eta+3.2838 .
$$



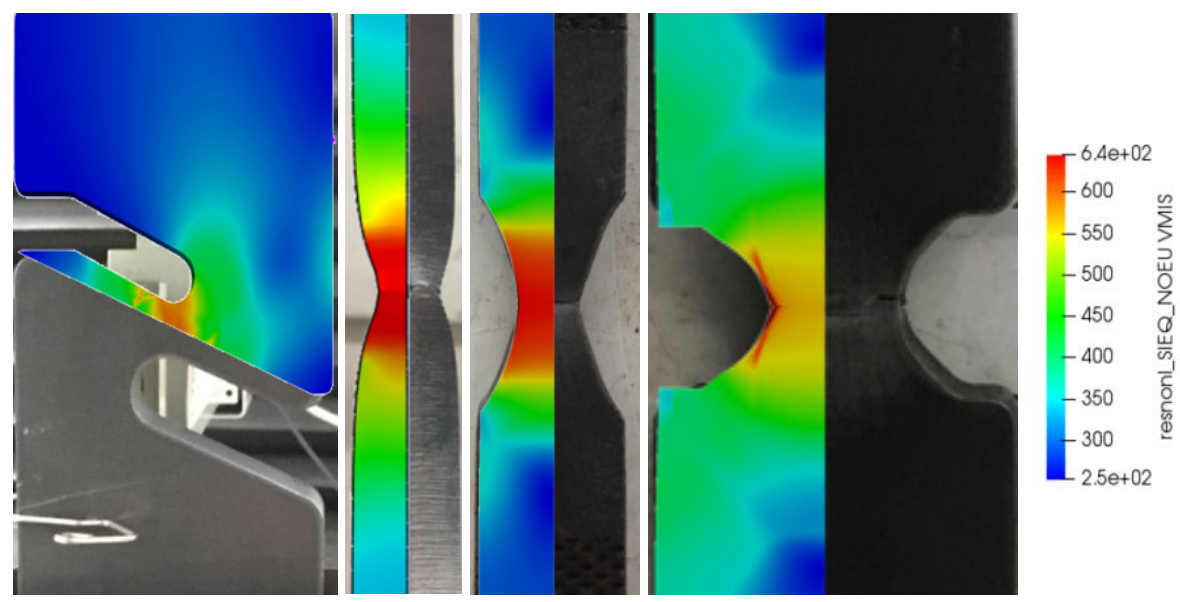

Figure 4: Numerical models of the test to retrieve plastic strain at fracture; from left geometries \#1, \#2, \#3 and \#4 (von Mises stress).

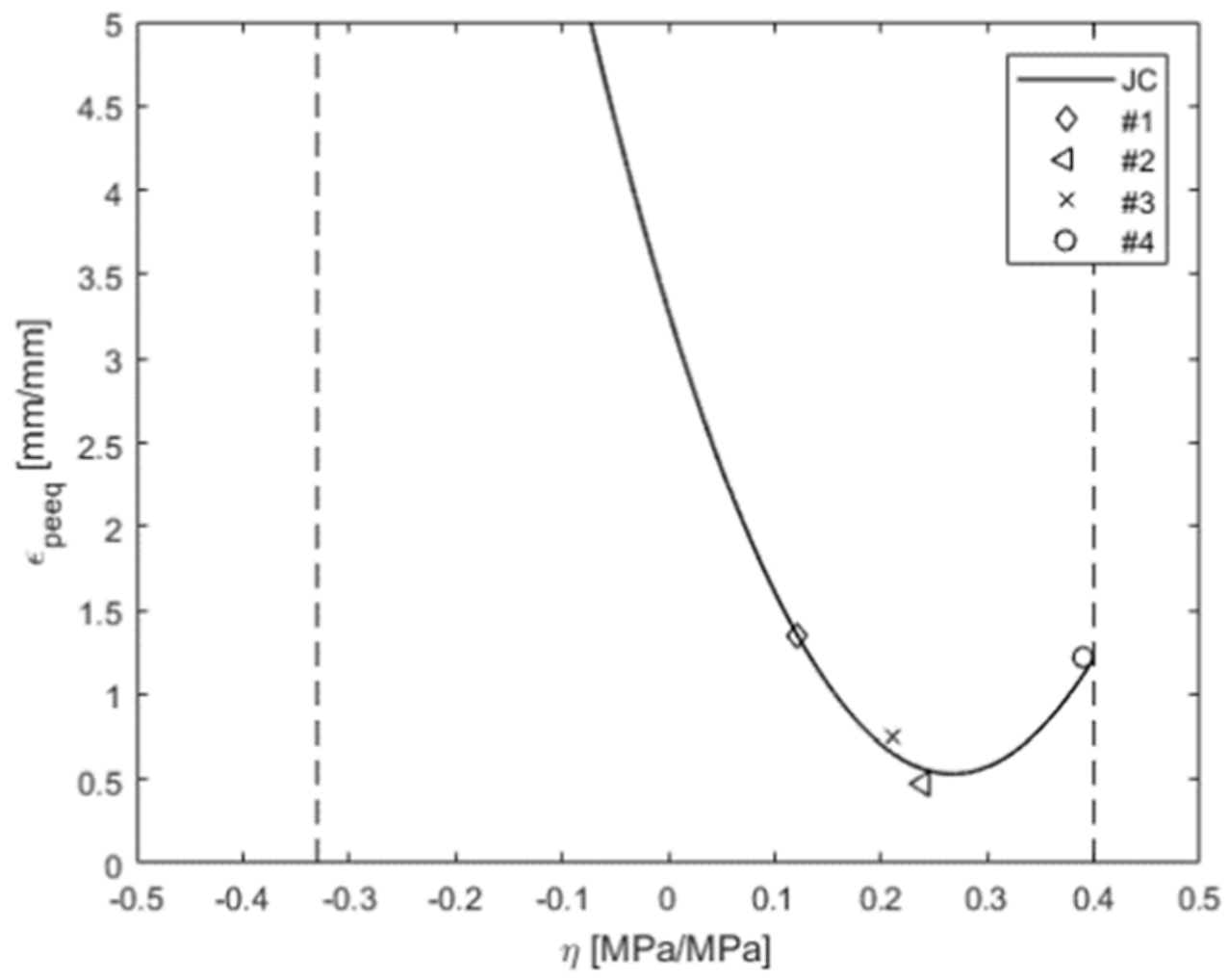

Figure 5: Fracture locus. 

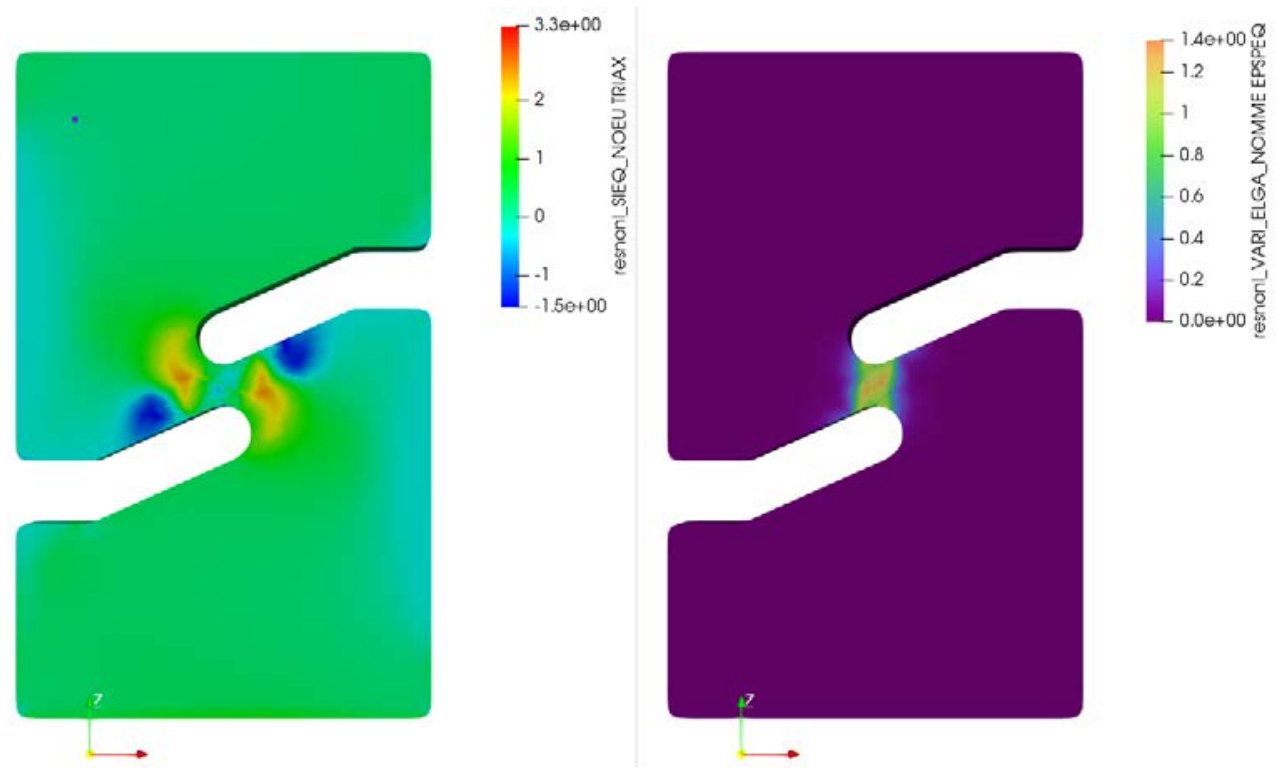

Figure 6: Triaxiality and equivalent plastic strain at fracture, sample \#1.

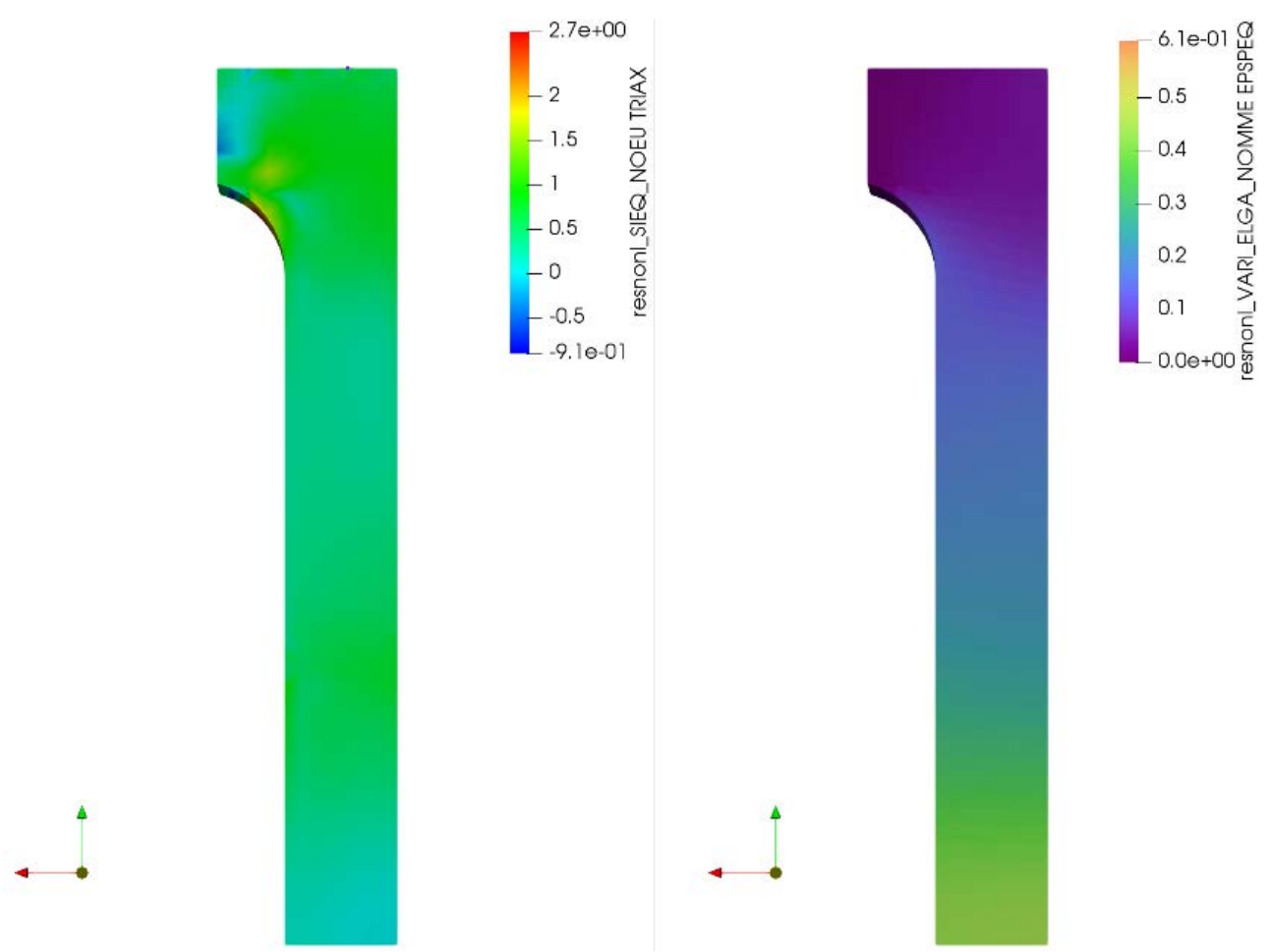

Figure 7: Triaxiality and equivalent plastic strain at fracture, sample \#2. 


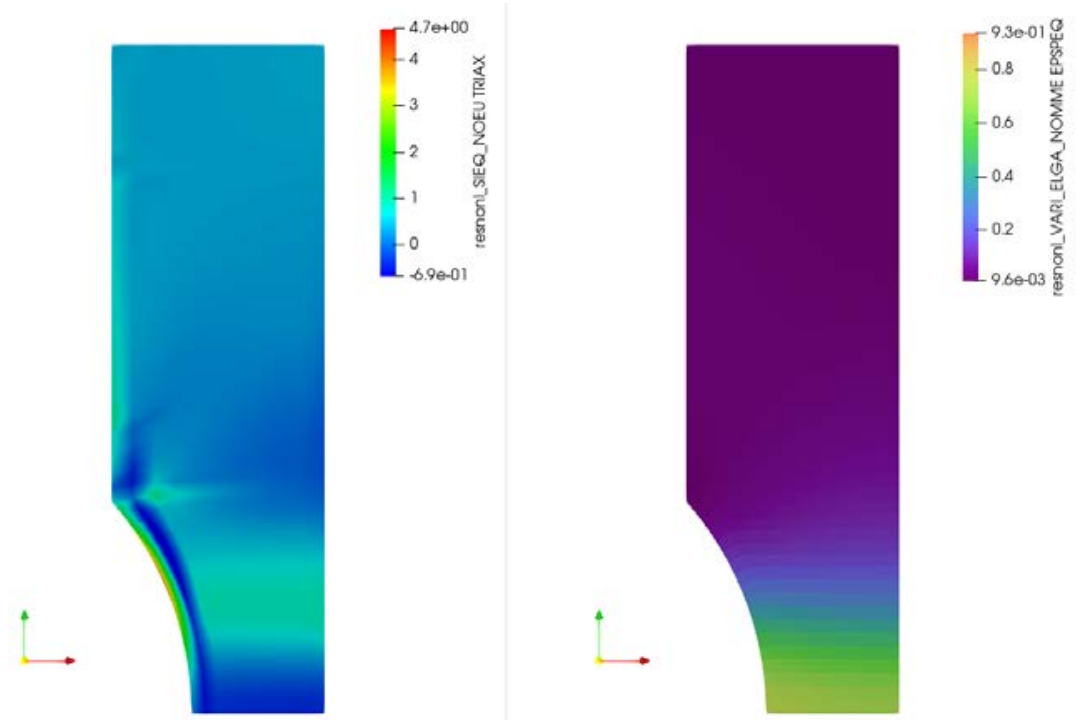

Figure 8: Triaxiality and equivalent plastic strain at fracture, sample \#3.

Table 2: Results of the calibration procedure: triaxiality $\eta$ and equivalent plastic strain at fracture $\varepsilon_{p e e q}$.

\begin{tabular}{|c|c|c|c|c|}
\cline { 2 - 5 } \multicolumn{1}{c|}{} & \multicolumn{4}{c|}{ Sample geometry } \\
\cline { 2 - 5 } \multicolumn{1}{c|}{} & $\# 1$ & $\# 2$ & $\# 3$ & $\# 4$ \\
\hline$\eta$ & 0.25 & 0.23 & 0.21 & 0.39 \\
\hline$\varepsilon_{\text {peeq }}$ & 1.35 & 0.475 & 0.753 & 1.22 \\
\hline
\end{tabular}
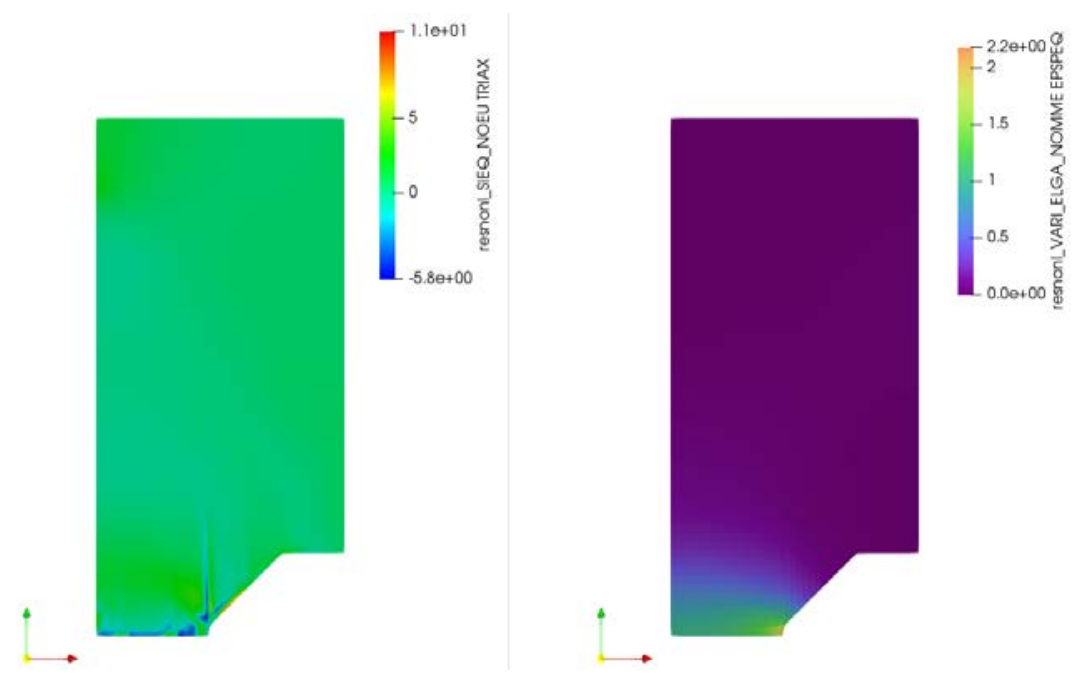

Figure 9: Triaxiality and equivalent plastic strain at fracture, sample \#4. 


\section{CONCLUSIONS}

In this research, a ductile fracture model has been calibrated for Cor-Ten weathering steel. The effect of strain rate and temperature has been neglected but will be included in future studies. The calibration of the fracture locus was performed by means of experimental tests on 4 different sample geometries. This characterization can thus be implemented through an FE model in order to study the plastic behavior of Cor-Ten during different situations. Future studies will be addressed to the study of the behavior of a guard rail in Cor-Ten, new and with some defects, during impact.

\section{ACKNOWLEDGEMENT}

The authors would like to thank A.ERRE [34] for the financial support.

\section{References}

[1] Decker, P., Brüggerhoff, S. \& Eggert, G., To coat or not to coat? The maintenance of Cor-Ten ${ }^{\circledR}$ sculptures. Materials and Corrosion., 59(3), pp. 239-247, 2008.

[2] Revie, R.W., Uhlig's Corrosion Handbook: Third Edition, Wiley: Hoboken, 2011.

[3] Dunkley, F.G., Painting of railway rolling stock. Journal of the Institution of Locomotive Engineers, 57(319), pp. 509-553, 1967.

[4] Fischer, M., Weathering steel in bridges. Structural Engineering International, 5(1), pp. 51-54, 1995.

[5] Mostafavi, D. \& Leatherbarrow, M., On Weathering: The Life of Buildings in Time, MIT: Cambridge, MA, 1993.

[6] Corten + Art, Pinterest. www.pinterest.it/trackdesign9867/corten+art/?lp=true.

[7] Kamimura, T., Hara, S., Miyuki, H., Yamashita, M. \& Uchida, H., Composition and protective ability of rust layer formed on weathering steel exposed to various environments. Corrosion Science, 48(9), pp. 2799-2812, 2006.

[8] Morcillo, M., Chico, B., Díaz, I., Cano, H. \& de la Fuente, D., Atmospheric corrosion data of weathering steels. A review. Corrosion Science, 77, pp. 6-24, 2013.

[9] Concli, F. et al., Load independent power losses of ordinary gears: Numerical and experimental analysis. 5th World Tribology Congress, WTC 2013, 2, 2013.

[10] S. RJ and G. WP, For architectural applications-unpainted high strength low alloy steel. Matls Prot., 8(12), pp. 70-77, 1969.

[11] Zhang, Q.C., Wu, J.S., Wang, J.J., Zheng, W.L., Chen, J.G. \& Li, A.B., Corrosion behavior of weathering steel in marine atmosphere. Materials Chemistry and Physics, 77(2), pp. 603-608, 2003.

[12] Wang, J.H., Wei, F.I., Chang, Y.S. \& Shih, H.C., The corrosion mechanisms of carbon steel and weathering steel in $\mathrm{SO} 2$ polluted atmospheres. Materials Chemistry and Physics, 47(1), pp. 1-8, 1997.

[13] Wang, R., Luo, S., Liu, M. \& Xue, Y., Electrochemical corrosion performance of Cr and $\mathrm{Al}$ alloy steels using a J55 carbon steel as base alloy. Corrosion Science, 85, pp. 270-279, 2014.

[14] Guo, J., Yang, S., Shang, C., Wang, Y. \& He, X., Influence of carbon content and microstructure on corrosion behaviour of low alloy steels in a $\mathrm{Cl}^{-}$containing environment. Corrosion Science, 51(2), pp. 242-251, 2009.

[15] Chiavari, C., Bernardi, E., Martini, C., Passarini, F., Motori, A. \& Bignozzi, M.C., Atmospheric corrosion of Cor-Ten steel with different surface finish: Accelerated ageing and metal release. Materials Chemistry and Physics, 136(2-3), pp. 477-486, 2012.

[16] Autostrada del Brennero SpA Brennerautobahn AG. 
www.autobrennero.it/documenti/4Areatecnica/Pubblicazioni/2010/barrieresicurezza A22.pdf.

[17] Autostrada del Brennero SpA Brennerautobahn AG. Design and Testing of Safety Barriers of their own Design for the Benefit of User. www.autobrennero.it/it/la-reteautostradale/la-sicurezza/barriere-sicurezza/.

[18] Deflorian, F. \& Rossi, S., Premature corrosion failure of structural highway components made from weathering steel. Engineering Failure Analysis, 9(5), pp. 541$551,2002$.

[19] Whitworth, H.A., Bendidi, R., Marzougui, D. \& Reiss, R., Finite element modeling of the crash performance of roadside barriers. International Journal of Crashworthiness, 9(1), pp. 35-43, 2004.

[20] Ren, Z. \& Vesenjak, M., Computational and experimental crash analysis of the road safety barrier. Engineering Failure Analysis, 12(6), pp. 963-973, 2005.

[21] Voce, E., A practical strain-hardening function. Metallurgia, 51, pp. 219-226, 1955.

[22] Voce, E., The relationship between stress and strain for homogeneous deformation. Journal of the Institute of Metals, 74, pp. 537-562, 1948.

[23] Mirza, M.S., Barton, D.C, Church, P. \& Sturges, J.L., Ductile fracture of pure copper: An experimental and numerical study. Journal De Physique. IV (Proceedings), 7(3), pp. C3-891-C3-896, 1997.

[24] Rice, J.R. \& Tracey, D.M., On the ductile enlargement of voids in triaxial stress fields. Journal of the Mechanics and Physics of Solids, 17(3), pp. 201-217, 1969.

[25] Hancock, J.W. \& Mackenzie, A.C., On the mechanisms of ductile failure in highstrength steels subjected to multi-axial stress-states. Journal of the Mechanics and Physics of Solids, 24(2-3), pp. 147-160, 1976.

[26] Johnson, G.R. \& Cook, W.H., A constitutive model and data for metals subjected to large strains, high strain rates and high temperatures. Proceedings of the 7th International Symposium on Ballistics, pp. 541-547, 1983.

[27] Bao, Y. \& Wierzbicki, T., On fracture locus in the equivalent strain and stress triaxiality space. International Journal of Mechanical Sciences, 46(1), pp. 81-98, 2004.

[28] Bao, Y., Prediction of Ductile Crack Formation in Uncracked Bodies, Massachusetts Institute of Technology: Cambridge, MA, 2003.

[29] Bao, Y., Dependence of ductile crack formation in tensile tests on stress triaxiality, stress and strain ratios. Engineering Fracture Mechanics, 72(4), pp. 505-522, 2005.

[30] Gilioli, A., Manes, A., Giglio, M. \& Wierzbicki, T., Predicting ballistic impact failure of aluminium 6061-T6 with the rate-independent Bao-Wierzbicki fracture model. International Journal of Impact Engineering, 76, pp. 207-220, 2015.

[31] Suárez, F., Gálvez, J.C., Cendón, D.A. \& Atienza, J.M., Distinct fracture patterns in construction steels for reinforced concrete under quasistatic loading-A review. Metals, 8(3), pp. 171, 2018.

[32] Concli, F. \& Gilioli, A., Numerical and experimental assessment of the static behavior of 3D printed reticular Al structures produced by Selective Laser Melting: progressive damage and failure. Procedia Structural Integrity, 12, pp. 204-212, 2018.

[33] Concli, F., Gilioli, A. \& Nalli, F., Experimental-numerical assessment of ductile failure of Additive Manufacturing selective laser melting reticular structures made of Al A357. Proceedings of the Institution of Mechanical Engineers, Part C: Journal of Mechanical Engineering Science, 2019.

[34] A.ERRE Srl. di Serravalle Pistoiese (PT), Italy. www.aerrecarpenteria.it/. 